\title{
Sepsis risk factors in infants with congenital diaphragmatic hernia
}

\author{
Michaël Levy ${ }^{1,2}$, Nolwenn Le Sache ${ }^{1,2}$, Mostafa Mokhtari ${ }^{2}$, Guy Fagherazzi ${ }^{3}$, Gaelle Cuzon ${ }^{4}$, Benjamin Bueno ${ }^{1}$,
} Virginie Fouquet ${ }^{2,5,6}$, Alexandra Benachi ${ }^{2,6,7}$, Sergio Eleni Dit Trolli ${ }^{1,2,8}$ and Pierre Tissieres ${ }^{1,2,6,8^{*}} \mathbb{E}$

\begin{abstract}
Background: Congenital diaphragmatic hernia $(C D H)$ is a rare congenital anomaly and remains among the most challenging ICU-managed disease. Beside severe pulmonary hypertension, lung hypoplasia and major abdominal surgery, infective complications remain major determinants of outcome. However, the specific incidence of sepsis as well as associated risk factors is unknown.

Methods: This prospective, 4-year observational study took place in the pediatric intensive care and neonatal medicine department of the Paris South University Hospitals (Le Kremlin-Bicêtre, France), CDH national referral center and involved 62 neonates with $\mathrm{CDH}$.

Main results: During their ICU stay, 28 patients (45\%) developed 38 sepsis episodes. Ventilator-associated pneumonia (VAP: 23/38; 31.9 VAP per 1000 days of mechanical ventilation) and central line-associated blood stream infections (CLABSI: 5/38; 5.5 per 1000 line days) were the most frequently encountered infections. Multivariate analysis showed that gestational age at birth and intra-thoracic position of liver were significantly associated with the occurrence of sepsis. Infected patients had longer duration of mechanical and noninvasive ventilation (16.2 and 5.8 days, respectively), longer delay to first feeding (1.2 days) and a longer length of stay in ICU (23 days), but there was no difference in mortality.

Conclusions: Healthcare-associated infections, and more specifically VAP, are the main infective threat in children with CDH. Sepsis has a significant impact on the duration of ventilator support and ICU length of stay but does not impact mortality. Low gestational age and intra-thoracic localization of the liver are two independent risk factors associated with sepsis.
\end{abstract}

Keywords: Congenital diaphragmatic hernia, Sepsis, Healthcare-associated infection, Ventilator-associated pneumonia, Central line-associated bloodstream infection

\section{Background}

Congenital diaphragmatic hernia $(\mathrm{CDH})$ is a rare congenital anomaly of the diaphragm with an incidence of approximately $1-3.5$ per 10,000 births [1-3]. CDH patients suffer from severe respiratory failure caused by a combination of defect in the muscular or tendinous portion of the diaphragm, pulmonary hypoplasia and

\footnotetext{
*Correspondence: pierre.tissieres@aphp.fr

1 Pediatric Intensive Care and Neonatal Medicine, Paris South University Hospitals, Assistance Publique Hôpitaux de Paris, 78, Rue du Général Leclerc, 94270 Le Kremlin-Bicêtre, France

Full list of author information is available at the end of the article
}

persistent pulmonary hypertension (PAH) [4]. Once the diaphragm is surgically repaired, lung morbidities are considered to be the main determinant for postnatal outcome, resulting in an overall survival rate up to $84 \%$ [5]. With the improvement in neonatal care of children with $\mathrm{CDH}$, other factors than pulmonary hypoplasia and PAH impact on the prognosis like nutrition and infections $[6,7]$. It is recognized that following the initial neonatal period, recurrent respiratory infections are frequently reported complications and are responsible for most hospital readmissions [7]. However, there are very few data concerning sepsis and healthcare-associated infection (HCAI) in this population and its impact on prognosis. 
The aim of this study is to evaluate the incidence of sepsis and HCAI in children with $\mathrm{CDH}$ and to identify the associated risk factors.

\section{Methods}

We performed prospective, monocentric study that included all consecutive neonates born with a $\mathrm{CDH}$ who were between December 2009 and January 2015 in the neonatal intensive care unit of the Paris South University Hospitals in Kremlin-Bicêtre, France. Our center is a national referral center for CDH management. During the study period, 161 pregnant mothers with prenatally diagnosed $\mathrm{CDH}$ were referred from other centers for antenatal evaluation for potential inclusion in fetal tracheal occlusion (FETO) trials (AB; TOTAL Trial 1 NCT007637737; TOTAL Trial 2 NCT01240057). Subsequently, 82 (51\%) with the most severe $\mathrm{CDH}$ form were selected and oriented to our center for perinatal management. These patients were identified from a prospectively maintained database of all newborn admitted in our unit with congenital diaphragmatic hernia. In addition, patients with sepsis were identified in a prospective HCAI and sepsis surveillance program and matched with the institutional program of medicalization of information systems (PMIS) database using the 10th version of the International Classification of Diseases. All newborns dying within the first 3 days of life were excluded. Additional data missing in the prospective database were retrospectively collected from patient's files. All patients' data were secondarily anonymized. Children representatives were informed. The study was reviewed by the Ethic Committee of the French Society of Intensive Care (Société de Reanimation de Langue Française), which waived the need of parents signed informed consent (CE SRLF-15-38).

The primary endpoint was to describe the incidence of sepsis in children with $\mathrm{CDH}$. Secondary endpoints were the identification of associated risk factors and to evaluate the impact on patients' outcome. The following data were collected for all patients: sex, gestational age at birth, gestational age at diagnosis, birth weight, hernia type (right or left), best observed/expected lunghead ratio (O/E LHR), intra-thoracic position of liver, the period of diagnosis (ante versus postnatal), fetal tracheal occlusion (FETO) during pregnancy, antenatal steroid therapy, delay between delivery and surgery, presence of surgical abdominal plate or chest tube, use of various catheters (umbilical venous and artery catheters, peripheral arterial catheter, centrally inserted central venous catheter (CVC) and peripherally inserted central catheter (PICC). Sepsis was defined as clinical symptoms of infection and/or sudden clinical deterioration together with significant increase in C-reactive protein (CRP) and/ or procalcitonin (PCT). Healthcare-associated infections were defined according to the 2016 update of Center for Disease Control HCAI criteria (Additional file 1: Table S1) $[8,9]$.

Data on infection were also collected: type of infection, presence of septic shock, identification of bacteria, temperature, CRP, PCT, leukocyte and neutrophil counts, initial antibiotic therapy and duration, time to first negative PCT. The outcome data were durations of mechanical ventilation, duration of high-frequency oscillatory ventilation (HFOV), duration of noninvasive ventilation, time to first day of feeding, weight at day five, presence of $\mathrm{PAH}$, use of pulmonary vasodilators, use of inotrope treatments, length of hospitalization stay and death.

The results of the descriptive analysis were expressed as numbers and percentages for qualitative variables and as mean and standard deviation for quantitative variables. Two-tailed Fisher's exact test for quantitative variables and Chi-square test for qualitative variable were used. Risk of infection was modeled using a multivariate logistical regression analysis. A stepwise selection was used, and the final model was adjusted on all variables associated with a $p$ value below 0.2 .

\section{Results}

\section{Patients characteristics}

Eighty-two children were hospitalized during the study period. Sixteen children died within the first 3 days of life (38\% of right $\mathrm{CDH}$, no sepsis), and two additional patients were excluded because the diagnosis was made after the neonatal period (2.4 and 6 months after birth). The 62 remaining newborns (all inborn) were included in the study. Patients' characteristics are described in Table 1. The mean gestational age at birth was $38.4 \pm 2.2$ weeks and the mean birth weight was $3072 \pm 671 \mathrm{~g}$. Ten patients $(16 \%)$ were preterm. Most patients had leftsided $\mathrm{CDH}(90 \%, n=56)$ and $38.7 \%$ of the patients had an intra-thoracic ascension of liver $(n=24) .83 .9 \%$ of the patients $(n=52)$ were diagnosed during pregnancy, the mean age of $\mathrm{CDH}$ diagnosis was $27.6 \pm 7.4$ weeks and the mean of O/E LHR was $42.1 \%$. Seven patients $(11.3 \%)$ underwent a FETO procedure during pregnancy and nine (14.5\%) had antenatal steroids. The mean length of hospitalization was $21.9 \pm 27.8$ days.

\section{Description of sepsis episodes}

Twenty-eight patients (45\%) developed 38 sepsis episodes during the hospitalization period. Four patients developed two different sepsis episodes, one patient developed three and one patient developed five episodes during the hospitalization. Clinical and laboratory findings are presented in Table 2. VAP was the main cause of sepsis and accounted for $60.5 \%$ of all cases (23/38) with 
Table 1 Patients characteristics

\begin{tabular}{|c|c|c|c|}
\hline & No sepsis $(n=34)$ & Sepsis $(n=28)$ & $p$ value* \\
\hline Gender (male) & $26(76.5 \%)$ & $19(67.9 \%)$ & 0.57 \\
\hline Gestational age at birth (weeks) & $38.8(2.1)$ & $37.8(2.2)$ & 0.09 \\
\hline \multicolumn{4}{|l|}{ Term of birth } \\
\hline Preterm (<37 weeks) & $4(11.8 \%)$ & $6(21.4 \%)$ & 0.49 \\
\hline Term ( $\geq 37$ weeks) & $30(88.2 \%)$ & $22(78.6 \%)$ & 0.79 \\
\hline$\geq 37$ and $<39$ weeks & 8 & 11 & \\
\hline$\geq 39$ and $<42$ weeks & 22 & 11 & \\
\hline Birth weight (g) & $3092(633)$ & $3048(726)$ & \\
\hline Gestational age at diagnosis (weeks) & $30.0(7.5)$ & $25.1(6.3)$ & $<0.01$ \\
\hline \multicolumn{4}{|l|}{ Type } \\
\hline Left & $31(91.2 \%)$ & $25(89.3 \%)$ & 0.80 \\
\hline Right & $3(8.8 \%)$ & $3(10.7 \%)$ & \\
\hline Best observed/expected LHR (\%) & $47.2 \pm 12.2$ & $37.8 \pm 12.5$ & 0.02 \\
\hline Intra-thoracic liver & $7(21.2 \%)^{* 1}$ & 17 (60\%) & $<0.01$ \\
\hline Antenatal diagnosis & $26(76.5 \%)$ & $26(92.8 \%)$ & 0.08 \\
\hline FETO & $3(8.8 \%)$ & $4(14.3 \%)$ & 0.49 \\
\hline Antenatal steroids & $1(2.9 \%)$ & $8(28.6 \%)$ & $<0.01$ \\
\hline Time before surgery (days) & $2.26(1.9)$ & $2.14(1.0)$ & 0.74 \\
\hline Patch repair & $4(12.5 \%)^{* 2}$ & $13(46.4 \%)$ & $<0.01$ \\
\hline Chest tube & $7(25.9 \%)^{* 2}$ & $4(12.5 \%)^{* 1}$ & 0.18 \\
\hline Umbilical venous catheter & $29(85.3 \%)$ & $26(92.9 \%)$ & 0.34 \\
\hline Umbilical arterial catheter & $4(11.8 \%)$ & $3(10.7 \%)$ & 0.89 \\
\hline Arterial catheter & $2(5.8 \%)$ & $5(17.9 \%)$ & 0.13 \\
\hline Central venous catheter & $17(50.0 \%)$ & $26(92.9 \%)$ & $<0.01$ \\
\hline Peripherally inserted central venous catheter & $9(26.5 \%)$ & $10(35.7 \%)$ & 0.43 \\
\hline
\end{tabular}

Values are expressed as number (\%), or mean $\pm S D$

${ }^{*} X$ number of missing data; LHR lung-to-head ratio; FETO fetal tracheal occlusion

* Univariate analysis

an incidence density of 31.9 per 1000 days of mechanic ventilation. VAP was followed by CLABSI (5/38, 5.5 per 1000 line days, $13.2 \%$ of the infections) and by urinary tract infections and bacteremia with no source identified. Forty-seven centrally inserted CVC were used in 43 patients including 31 left subclavian vein, 15 internal jugular veins and one femoral vein CVC. CLABSI occurred in $3 / 47(6.4 \%)$ centrally inserted CVC and in $2 / 19(10.5 \%)$ PICC. Sepsis occurred after a mean of $22.4 \pm 33.1$ days of hospitalization. The mean time to develop VAP was $25.5 \pm 36.1$ days, and CLABSI was $35.6 \pm 41.9$ days. Most patients $(65.8 \%)$ had fever, while $15.8 \%$ had hypothermia at diagnosis. Mean CRP value was $103.2 \pm 73.5 \mathrm{mg} / \mathrm{L}$, and mean PCT value was $10.5 \pm 21.2 \mu \mathrm{g} / \mathrm{L}$. The main bacteria identified were Escherichia coli (22\%), Staphylococcus epidermidis (19.5\%), Staphylococcus aureus (14.6\%) and Enterobacter cloacae (9.8\%). Vancomycin, piperacillin-tazobactam, cefotaxime, gentamicin and amikacin were the main antibiotics used following unit protocoled antibiotic therapy. Antibiotics were adapted to the bacteria and its resistance profile in all cases. Bacteria were identified in $89 \%$ of all sepsis. The mean time to normal PCT was $6.5 \pm 3.4$ days, and the mean duration of antibiotic therapy was $8.02 \pm 2.41$ days.

\section{Risk factors for infection}

Using univariate comparison (Table 1), infected patients had a significant lower gestational age at diagnosis, lower observed/expected LHR than non-infected patients $(\mathrm{O} / \mathrm{E}$ LHR range $12.5-65$ vs. 27.1-69, respectively) and more use of antenatal steroids. Intra-thoracic liver, use of surgical plate and $\mathrm{CVC}$ were also more frequent in infected patients. The difference between the two groups regarding gender, gestational age at birth, proportion of preterm, birth weight, type of hernia, FETO, delay between delivery and surgery, requirement of a chest tube, umbilical venous and arterial catheters, peripheral arterial catheter and PICCs was not significant. After multivariate logistical regression analysis and a stepwise selection of variables (Table 3), the gestational age at birth (in weeks), the birth weight (in grams), an intra-thoracic position of liver and the presence of a centrally inserted $\mathrm{CVC}$ were 
Table 2 Sepsis characterization

\begin{tabular}{ll}
\hline Data & $\boldsymbol{N}(\%)$ or mean (SD) \\
\hline Number of sepsis episodes* & 38 \\
Type of sepsis & \\
Meningitis & $1(2.6 \%)$ \\
Ventilator-associated pneumonia & $23(60.5 \%)$ \\
Same side as hernia & $6(26 \%)$ \\
Opposite side as hernia & $11(48 \%)$ \\
Both lungs & $6(26 \%)$ \\
Urinary tract infection & $3(7.9 \%)$ \\
With urinary catheter & $1(2.6 \%)$ \\
Without urinary catheter & $2(5.3 \%)$ \\
Central line-associated bloodstream infection & $5(13.2 \%)$ \\
Central venous catheter & $3(7.9 \%)$ \\
Peripherally inserted central catheter & $2(5.3 \%)$ \\
Bacteremia with no origin found & $3(7.9 \%)$ \\
Early-onset neonatal sepsis & $2(5.3 \%)$ \\
Surgical site infection & $1(2.6 \%)$ \\
Septic shock & $7(18.4 \%)$ \\
Delay between delivery and sepsis (days) & \\
All infections & $22.4(33.1)$ \\
VAP & $25.5(36.1)$
\end{tabular}

$N$ number, $S D$ standard deviation, VAP ventilator-associated pneumonia * In 28 patients

Table 3 Multivariate analysis of risk factor for sepsis

\begin{tabular}{lcll}
\hline & $\begin{array}{l}\text { Odds } \\
\text { ratio }\end{array}$ & $\begin{array}{l}\text { Wald-type } \\
\mathbf{9 5 \% ~ C l}\end{array}$ & p value \\
\hline $\begin{array}{l}\text { Gestational age at birth } \\
\text { (weeks) }\end{array}$ & 0.439 & $0.224-0.862$ & 0.016 \\
$\begin{array}{l}\text { Birth weight (grams) } \\
\text { Right CDH }\end{array}$ & 1.003 & $1.001-1.006$ & 0.012 \\
$\begin{array}{l}\text { Intra-thoracic liver } \\
\begin{array}{l}\text { Centrally inserted venous } \\
\text { catheter }\end{array}\end{array}$ & 0.894 & $0.783-1.022$ & 0.099 \\
$\begin{array}{l}\text { Peripherally inserted central } \\
\text { catheter }\end{array}$ & 3.836 & $1.439-48.104$ & 0.018 \\
\hline
\end{tabular}

significantly associated with the occurrence of an infection. With every additional week of gestation at birth, the OR of contracting an infection was 0.439 (95\% CI 0.224-0.862). Although most children with sepsis had a centrally inserted CVC (26/28), outlining the severity of those patients, very few developed a CLABSI.

\section{Impact of sepsis on patients' outcome}

Infected patients had significantly poorer prognosis than non-infected patients (Table 4). Infected patients had longer duration of mechanical ventilation, longer
Table 4 Impact of sepsis on patients' outcomes

\begin{tabular}{|c|c|c|c|}
\hline & $\begin{array}{l}\text { Sepsis } \\
(n=28)\end{array}$ & $\begin{array}{l}\text { No sepsis } \\
(n=34)\end{array}$ & $\begin{array}{l}p \text { value or } \\
\text { OR }(95 \% \mathrm{Cl})\end{array}$ \\
\hline $\begin{array}{l}\text { Duration of mechanical } \\
\text { ventilation (days) }\end{array}$ & $20.5(15.6)$ & $4.3(4.0)$ & $<0.0001$ \\
\hline Duration of HFOV (days) & $10.2(9.9)$ & $1.2(2.4)$ & $<0.0001$ \\
\hline $\begin{array}{l}\text { Duration of noninvasive } \\
\text { ventilation (days) }\end{array}$ & $6.9(12.3)$ & $1.1(2.4)$ & $<0.01$ \\
\hline $\begin{array}{l}\text { Time to first day } \\
\text { of feeding (days) }\end{array}$ & $6.0(2.3)$ & $4.8(2.0)$ & 0.049 \\
\hline Weight at day 5 (g) & $3246(769)$ & $3076(644)$ & 0.37 \\
\hline $\begin{array}{l}\text { Duration of } \\
\text { hospitalization (days) }\end{array}$ & $34.6(35.9)$ & $11.6(11.6)$ & $<0.001$ \\
\hline Volemic expansion* & $21(75.0 \%)$ & $14(41.1 \%)$ & $4.2(1.4-12.8)$ \\
\hline Inotrope treatment* & $24(85.7 \%)$ & $17(50.0 \%)$ & $5.9(1.7-21.0)$ \\
\hline NO treatment ${ }^{*}$ & $20(71.4 \%)$ & $9(26.4 \%)$ & $6.9(2.2-21.2)$ \\
\hline $\mathrm{PAH}^{*}$ & 27 (96.4\%) & $27(79.4 \%)$ & $7.0(0.8-60.0)$ \\
\hline Death* & $7(25.0 \%)$ & $5(14.7 \%)$ & $1.9(0.6-6.9)$ \\
\hline
\end{tabular}

Values are expressed as mean (SD) or * number (percent)

$\mathrm{OR}$ odd ratio, HFOV high-frequency oscillatory ventilation, NO nitric oxide, $P A H$ pulmonary arterial hypertension defined as tricuspid regurgitation $>3 \mathrm{~m} / \mathrm{s}$ associated with right ventricle and septal signs of $\mathrm{PAH}$

duration of noninvasive ventilation, longer delay to first feeding and longer duration of hospitalization. Infected patients also requested significantly more inotrope treatment, fluid resuscitation and red blood cells transfusion (data not shown). There was no significant difference in death rate in the two groups.

\section{Discussion}

The major finding of this study is that lower gestational age at birth is independently associated with sepsis and HCAI in children with $\mathrm{CDH}$, representing a major risk factor for associated morbidities. Similarly, following neonatal congenital heart surgery, HCAI is known to be associated with prolonged length of stay in ICU as well as increased mortality and costs [10-14].

Although HCAI is representing the vast majority of sepsis (30/38), VAP is clearly emerging as the main cause of infection in this subset of neonatal patients. The prevalence of VAP in this population (31.9 per 1000 ventilator days) is higher than in other neonates admitted in our unit during the same period of time (2009-2014) with a mean of 16.5 per 1000 ventilator days (yearly range 9.1-19.3 per 1000). In most studies, rate of VAP varies between 0.2 and 10.9 per 1000 ventilator days, and a recent meta-analysis found a prevalence ranging from 8.1 to $57.1 \%$ [9, 15-17]. Beside local prevention bundles application, the mechanism by which neonates with $\mathrm{CDH}$ have higher rates of VAP is not clear. A susceptibility to pulmonary infection could be explained by lung hypoplasia including fewer alveoli, reduced vascular bed 
and a certain degree of reduced ciliary epithelium. The fact that the most severe cases (with liver up) were more prone to infection is in favor of this hypothesis. Hypoplastic lung immunity might not be as efficient as in normal lungs, explaining why children with $\mathrm{CDH}$ have an increased sensitivity to the development of VAP. Some indirect observations are supporting this hypothesis. It was shown that adult patients with pulmonary fibrosis have increased bacterial burden due to poorer lung vascularization [18]. Although altered immunity has not been described in neonates with $\mathrm{CDH}$, recently, it was shown that peak inspiratory pressure impacts sphingomyelin degradation in $\mathrm{CDH}$ patients outlining the effects of ventilation on lung cell apoptosis and homeostasis [19]. Furthermore, role of mechanical ventilation in potentializing the innate immune response to bacteria and subsequent development of VAP is now well validated [20]. In neonates with $\mathrm{CDH}$ and hypoplastic lung, mechanical ventilation is associated with a high risk of barotrauma potentially aggravating secondary bacterial insults on lung parenchyma.

In our $\mathrm{CDH}$ cohort, we observed a microbiological shift in VAP pathogen. It is usually considered that in neonatal VAP, the most prevalent monomicrobial pathogens are $P$. aeruginosa, K. pneumonia and S. aureus, whereas polymicrobial VAP accounted for $6-58 \%$ of the cases [9]. In our series, few polymicrobial infections (3/38 episodes) were observed, and we did not found any infection due to $P$. aeruginosa but a high proportion of other Gramnegative bacteria, including $E$. coli and E. cloacae. In our patients, CLABSI is the second cause of sepsis. It is difficult to compare CLABSI incidence rate (5.5 par 1000 line days) to the neonatal literature (ranging between 1.43 and 11 per 1000 line days), considering that most studies include neonates from all terms (including very low birth weights) and that most neonatal units are using preferentially PICC and not centrally inserted CVC as routine practice [21-25]. Nevertheless, neonatal CLABSI incidence rates are mainly caused by $S$. epidermidis and $S$. aureus [26]. In our series, although Gram-negative sepsis burden was high (55.2\%), there was no CLABSI caused by enterobacteria.

We found that children with older gestational age at delivery have reduced risk of developing an infection in the course of hospitalization. This result leads to the question of the best timing of delivery of neonates with $\mathrm{CDH}$. The CDH Study Group reported increased survival among prenatally diagnosed $\mathrm{CDH}$ infants born at early-term ages (37-38 weeks of gestation), compared with infants born at later term ages (39-41 weeks of gestation) hypothesizing an increasing severity of lung hypoplasia with advancing gestational age [27]. However, the results have been challenged, and other studies found that neonates with $\mathrm{CDH}$ seemed to have inferior neonatal and infant mortality with the increase in the gestational age of birth [28-31]. Although most patients are less than 39 and more than 37 weeks of gestational age, our results clearly outline the impact of lower gestational age at delivery as a major perioperative risk factor for infective complications. The intra-thoracic position of liver is also an independent risk factor for infection in our population. Infants with intra-thoracic liver are already known to have poorer neonatal outcome with greater death before discharge and increased risk of extracorporeal membrane oxygenation (ECMO) [32-35]. The importance of liver positioning is crucial for the outcome of patients, and its link to poorer long-term outcome has been well established $[32,36]$. Among the 17 infected patients with liver ascension, 12 developed a VAP adding to the probable hypothesis of a specific lung cause to the development of VAP. Controlateral pneumonia, in the socalled healthy lung, reinforces the barotrauma hypothesis and subsequent pathogenesis of VAP and raised the difficult question of optimal pressure/volume target ventilation $[20,37,38]$.

Despite its monocentric design, our cohort is characterized by a highly selected case load. Interestingly, mortality $(13 / 62 ; 21 \%)$ in our cohort is corresponding to those of the CDH Euro consortium (25\%) as recently shown, outlining the adequacy of our results with larger European $\mathrm{CDH}$ centers [38]. Although one can argue that most infections were HCAI, and presumably preventable, our study suggest that neonates managed for $\mathrm{CDH}$ have an increased risk of developing sepsis and more specifically VAP compared to the general neonatal ICU patients. During the same period of time, in our unit, VAP incidence in $\mathrm{CDH}$ patients $(23 / 62,37.4 \%)$ was much higher than in the rest of patients ventilated for $>12 \mathrm{~h}(68 / 715,9.5 \%)$. Furthermore, the high incidence of VAP despite local VAP prevention bundles should raise the possibility that children with the most severe form of $\mathrm{CDH}$ have an intrinsic susceptibility to VAP. This has to be confirmed in multicenter cohort.

\section{Conclusion}

This study shows that neonates hospitalized for $\mathrm{CDH}$ have a high incidence of sepsis, mostly related to the development of VAP. We showed that the gestational age independently affects the risk of sepsis development. However, although the impact of sepsis on hospital morbidities is strong, sepsis has no effect on mortality in neonates with $\mathrm{CDH}$. This study urge confirmation and immunologic investigations aimed at studying susceptibility to infections of infants with $\mathrm{CDH}$ and particularly the physiopathologic basis of VAP in hypoplastic neonatal lung. 


\section{Additional file}

Additional file 1. Diagnostic criteria for health care associated infections (HCAl).

\section{Abbreviations}

$\mathrm{CDH}$ : congenital diaphragmatic hernia; CLABSI: central line-associated bloodstream infections; CSF: cerebrospinal fluid; CVC: central venous catheter; FETO: fetal tracheal occlusion; HCAl: healthcare-associated infection; HFOV: highfrequency oscillatory ventilation; NO: nitric oxide; O/E LHR: observed/expected lung-head ratio; PICC: peripherally inserted central catheter; $\mathrm{PAH}$ : pulmonary arterial hypertension; VAP: ventilator-associated pneumonia.

\section{Authors' contributions}

ML, SEDT, PT were involved in study conception and design; ML, NLE, GC, BB, GF, SEDT, MM, VF, AB PT were involved in acquisition, analysis, or interpretation of data. ML and GF were involved in statistical analysis. All authors contributed to drafting and revision of the work. All authors read and approved the final manuscript.

\section{Author details}

${ }^{1}$ Pediatric Intensive Care and Neonatal Medicine, Paris South University Hospitals, Assistance Publique Hôpitaux de Paris, 78, Rue du Général Leclerc, 94270 Le Kremlin-Bicêtre, France. ${ }^{2}$ Centre de référence Maladie Rare: Hernie de Coupole Diaphragmatique, 94270 Le Kremlin-Bicêtre, France. ${ }^{3}$ INSERM U1018, Center for Research in Epidemiology and Population Health (CESP), Paris South University, 94805 Villejuif, France. ${ }^{4}$ Bacteriology-Hygiene Unit, Paris South University Hospitals, Assistance Publique Hôpitaux de Paris, Le Kremlin-Bicêtre, France. ${ }^{5}$ Pediatric Surgery, Paris South University Hospitals, Assistance Publique Hôpitaux de Paris, Le Kremlin-Bicêtre, France. ${ }^{6}$ School of Medicine, Paris South University, UPS11, Le Kremlin-Bicêtre, France. ${ }^{7}$ Obstetrics, Gynecology and Reproductive Medicine, Antoine Béclère Hospital, Assistance Publique Hôpitaux de Paris, Clamart, France. ${ }^{8}$ Institute of Integrative Biology of the Cell, CNRS, CEA, Univ. Paris Sud, Paris Saclay University, Gif-sur-Yvette, France.

\section{Acknowledgements}

None.

\section{Competing interests}

The authors declare that they have no competing interests.

\section{Availability of data and materials}

The data cannot be deposited in publicly repositories since the agreement of the Ethic committee did not cover this aspect. However, we fully agree to discuss and share key data with interest individuals.

\section{Ethics approval and consent to participate}

The study was reviewed by the Ethic Committee of the French Society of Intensive Care (Société de Reanimation de Langue Française), which waived the need of parents signed informed consent (CE SRLF-15-38).

\section{Financial disclosure}

The authors have no financial relationship relevant to this article to disclose. No honorarium, grant or other form of payment was given to anyone to produce the manuscript.

Received: 27 November 2016 Accepted: 27 February 2017 Published online: 21 March 2017

\section{References}

1. Wright JCE, Budd JLS, Field DJ, et al. Epidemiology and outcome of congenital diaphragmatic hernia: a 9-year experience. Paediatr Perinat Epidemiol. 2011;25:144-9.

2. Torfs CP, Curry CJ, Bateson TF, et al. A population-based study of congenital diaphragmatic hernia. Teratology. 1992;46:555-65.
3. McGivern MR, Best KE, Rankin J, et al. Epidemiology of congenital diaphragmatic hernia in Europe: a register-based study. Arch Dis Child Fetal Neonatal Ed. 2015;100:F137-44.

4. Keijzer R, Puri P. Congenital diaphragmatic hernia. Semin Pediatr Surg. 2010:19:180-5

5. Tsao K, Lally KP. The Congenital Diaphragmatic Hernia Study Group: a voluntary international registry. Semin Pediatr Surg. 2008;17:90-7.

6. Muratore CS, Utter $\mathrm{S}$, Jaksic T, et al. Nutritional morbidity in survivors of congenital diaphragmatic hernia. J Pediatr Surg. 2001;36:1171-6.

7. Tracy S, Chen C. Multidisciplinary long-term follow-up of congenita diaphragmatic hernia: a growing trend. Semin Fetal Neonatal Med. 2014;19:385-91.

8. 2016 CDC's National Healthcare Safety Network Patient Safety Component Manual. http://www.cdc.gov/nhsn/pdfs/pscmanual/pcsmanual_ current.pdf.

9. Cernada M, Brugada M, Golombek S, et al. Ventilator-associated pneumonia in neonatal patients: an update. Neonatology. 2014;105:98-107.

10. Murray MT, Krishnamurthy G, Corda R, et al. Surgical site infections and bloodstream infections in infants after cardiac surgery. J Thorac Cardiovasc Surg. 2014;148:259-65.

11. Levy I, Ovadia B, Erez E, et al. Nosocomial infections after cardiac surgery in infants and children: incidence and risk factors. J Hosp Infect. 2003;53:111-6.

12. Pasquali SK, He X, Jacobs ML, et al. Hospital variation in postoperative infection and outcome after congenital heart surgery. Ann Thorac Surg. 2013:96:657-63.

13. Kansy A, Jacobs JP, Pastuszko A, et al. Major infection after pediatric cardiac surgery: external validation of risk estimation model. Ann Thorac Surg. 2012;94:2091-5.

14. Abou Elella R, Najm HK, Balkhy H, et al. Impact of bloodstream infection on the outcome of children undergoing cardiac surgery. Pediatr Cardiol. 2010;31:483-9.

15. Dudeck MA, Horan TC, Peterson KD, et al. National Healthcare Safety Network report, data summary for 2011, device-associated module. Am J Infect Control. 2013;41:286-300.

16. Kawanishi F, Yoshinaga M, Morita M, et al. Risk factors for ventilatorassociated pneumonia in neonatal intensive care unit patients. J Infect Chemother. 2014;20:627-30.

17. Tan B, Zhang F, Zhang X, et al. Risk factors for ventilator-associated pneumonia in the neonatal intensive care unit: a meta-analysis of observational studies. Eur J Pediatr. 2014;173:427-34.

18. Molyneaux PL, Cox MJ, Willis-Owen SAG, et al. The role of bacteria in the pathogenesis and progression of idiopathic pulmonary fibrosis. Am J Respir Crit Care Med. 2014;190:906-13.

19. Snoek KG, Reiss IKM, Tibboel J, et al. Sphingolipids in congenital diaphragmatic hernia; results from an international multicenter study. PLOS ONE. 2016;11:e0155136.

20. Ladoire S, Pauchard L-A, Barbar S-D, et al. Impact of the prone position in an animal model of unilateral bacterial pneumonia undergoing mechanical ventilation. Anesthesiology. 2013;118:1150-9.

21. Erdei C, McAvoy LL, Gupta M, et al. Is zero central line-associated bloodstream infection rate sustainable? A 5-year perspective. Pediatrics. 2015;135:e1485-93.

22. Shepherd EG, Kelly TJ, Vinsel JA, et al. Significant reduction of centralline associated bloodstream infections in a network of diverse neonatal nurseries. J Pediatr. 2015;167:41-6.e1-3. doi:10.1016/j.jpeds.2015.03.046.

23. Shalabi M, Adel M, Yoon E, et al. Risk of infection using peripherally inserted central and umbilical catheters in preterm neonates. Pediatrics. 2015;136:1073-924

24. de Brito CS, de Brito DVD, Abdallah VOS, et al. Occurrence of bloodstream infection with different types of central vascular catheter in critically neonates. J Infect. 2010;60:128-32.

25. Steiner M, Langgartner M, Cardona F, et al. Significant reduction of catheter-associated blood stream infections in preterm neonates after implementation of a care bundle focusing on simulation training of central line insertion. Pediatr Infect Dis J. 2015;34:1193-6.

26. Hooven TA, Polin RA. Healthcare-associated infections in the hospitalized neonate: a review. Early Hum Dev. 2014;90(Suppl 1):S4-6.

27. Stevens TP, van Wijngaarden E, Ackerman KG, et al. Timing of delivery and survival rates for infants with prenatal diagnoses of congenital diaphragmatic hernia. Pediatrics. 2009;123:494-502. 
28. Gorincour G, Bouvenot J, Mourot MG, et al. Prenatal prognosis of congenital diaphragmatic hernia using magnetic resonance imaging measurement of fetal lung volume. Ultrasound Obstet Gynecol. 2005;26:738-44.

29. Jani J, Nicolaides $\mathrm{KH}$, Keller RL, et al. Observed to expected lung area to head circumference ratio in the prediction of survival in fetuses with isolated diaphragmatic hernia. Ultrasound Obstet Gynecol. 2007;30:67-71.

30. Hutcheon JA, Butler B, Lisonkova S, et al. Timing of delivery for pregnancies with congenital diaphragmatic hernia. BJOG Int J Obstet Gynaecol. 2010;117:1658-62.

31. Ali K, Grigoratos D, Cornelius V, et al. Outcome of CDH infants following fetoscopic tracheal occlusion-influence of premature delivery. J Pediatr Surg. 2013:48:1831-6.

32. Lusk LA, Wai KC, Moon-Grady AJ, et al. Fetal ultrasound markers of severity predict resolution of pulmonary hypertension in congenital diaphragmatic hernia. Am J Obstet Gynecol. 2015;213(2):216.e1-8.

33. Lazar DA, Ruano R, Cass DL, et al. Defining "liver-up": does the volume of liver herniation predict outcome for fetuses with isolated left-sided congenital diaphragmatic hernia? J Pediatr Surg. 2012;47:1058-62.

34. Mullassery D, Ba'ath ME, Jesudason EC, et al. Value of liver herniation in prediction of outcome in fetal congenital diaphragmatic hernia: a systematic review and meta-analysis. Ultrasound Obstet Gynecol. 2010;35:609-14.

35. Jani J, Keller RL, Benachi A, et al. Prenatal prediction of survival in isolated left-sided diaphragmatic hernia. Ultrasound Obstet Gynecol. 2006;27:18-22.

36. Takayasu H, Masumoto K, Jimbo T, et al. Analysis of risk factors of longterm complications in congenital diaphragmatic hernia: a single institution's experience. Asian J Surg. 2017;40(1):1-5.

37. Reiss I, Schaible T, van den Hout $L$, et al. Standardized postnatal management of infants with congenital diaphragmatic hernia in Europe: the $\mathrm{CDH}$ EURO Consortium consensus. Neonatology. 2010;98:354-64.

38. Snoek KG, Capolupo I, van Rosmalen J, et al. Conventional mechanical ventilation versus high-frequency oscillatory ventilation for congenital diaphragmatic hernia: a randomized clinical trial (the VICl-trial). Ann Surg. 2016:263:867-74.

\section{Submit your manuscript to a SpringerOpen ${ }^{\circ}$ journal and benefit from:}

- Convenient online submission

- Rigorous peer review

- Immediate publication on acceptance

- Open access: articles freely available online

- High visibility within the field

- Retaining the copyright to your article 